\title{
Injury Epidemiyology in Elite Taekwondo Athletes: Retrospective Cross Sectional Study Including Three International Championships
}

\section{Elit Taekwondo Sporcularnda Yaralanma Epidemiyolojisi: Üç Uluslararası Şampiyonayı İçeren Kesitsel Retrospektif Çalışma}

\author{
Mehmet Mesut Çelebi ${ }^{1}$, İbrahim Dündar ${ }^{2}$, Ali Murat Zergeroğlu ${ }^{1}$ \\ ${ }^{1}$ Sports Medicine Department, Faculty of Medicine, Ankara University, Ankara, Turkey \\ ${ }^{2}$ Sports Medicine Department, Faculty of Medicine, Ahi Evran University, Kırşehir, Turkey
}

M. M. Çelebi

0000-0003-0581-6837

İ. Dündar

0000-0002-2451-4845

A. M. Zergeroğlu

0000-0002-5151-1375

Geliş Tarihi/Date Received: 28.02.2019

Kabul Tarihi/Date Accepted: 15.03.2019

Yayın Tarihi/Published Online: 21.03.2019

\section{Yazışma Adresi /}

Corresponding Author:

Mehmet Mesut Çelebi

Ankara Üniversitesi Tıp

Fakültesi Spor Hekimliği

Anabilim Dalı, Ankara

E-mail: mcelebi@ankara.edu.tr

C임 Türkiye Spor Hekimleri

Derneği. Tüm hakları saklıdır.

\begin{abstract}
Objective: In this retrospective cohort study, taekwondo (TWD) and para-taekwondo (P-TWD) injury rates, number of injuries and types of injuries were determined.

Material and Method: Injury incidences were recorded during $2^{\text {nd }}$ European Clubs Taekwondo Championship, $1^{\text {st }}$ International Open Taekwondo Championship and $3^{\text {th }}$ European ParaTaekwondo Championship which were held in Antalya. 1838 taekwondo and 74 para-taekwondo athletes were participated in 1521 taekwondo and in 59 parataekwondo competitions. The rate of injury were evaluated both as injuries per 1000 competions and per single competition. The injuries were recorded by 5 medical doctors. International Olympic Committee daily injury and illness report form was used for the injury records.
\end{abstract}

Results: 38 athletes were injured in 1580 competitions; 31 of them were taekwondo and 7 were para-taekwondo athletes. The incidence of injury was determined as 20,38 injuries/1000 competitions in taekwondo and 118,64 injuries/1000 competitions in parataekwondo. 0.02 injury per competion were recorded in teakwando and 0.11 injury per competition in para-taekwondo. Lower extremity injuries were found to be the most common injuries in para-taekwando (33,89 injuries/1000 competitions) and in taekwondo (10,51 injuries/1000 competitions).

Conclusion: The rate of injury in P-TWD was higher than in TWD. This study provides epidemiological information that will help to develop prevention strategies and recommendations for future injury monitoring studies and to reduce the number of injuries in taekwondo competitions.

Key Words: Taekwondo, Para-Taekwondo, Injury, Incidance

ÖZ

Objektif: Bu retrospektif kohort çalışmada taekwondo (TWD) ve para-tekwando (PTWD) müsabakalarında görülen yaralanma oranları, sayıları, türleri ve yaralanan vücut bölümleri belirlenmiştir.

Gereç ve Yöntem: Antalya'da yapılan 2. Avrupa Kulüpler Taekwondo Şampiyonası, 1. Uluslararası Türkiye Açık Taekwondo Şampiyonası ve 3. Avrupa Para-Taekwondo şampiyonalarında yer alan toplam 1838 taekwondo ve 74 para-taekwondo sporcusunun 1521 taekwando ve 59 para-taekwondo müsabakası sırasında karşılaştığı yaralanmalar kaydedilmiştir. 1000 müsabakadaki yaralanma oranı ve müsabaka başınayaralanma oranı değerlendirilmiştir. Yaralanmalar her biri tıp doktoru olan 5 
kişilik sağlık ekibi tarafından Uluslararası Olimpiyat Komitesinin günlük yaralanma ve hastalık raporu formu kullanılarak kaydedilmiştir.

Bulgular: 1580 müsabakada 31'i taekwando, 7'si para-taekwandoda olmak üzere 38 sporcu yaralanmıştır. Yaralanma insidansı taekwondoda 20,38 yaralanma/1000 müsabaka, para-taekwondoda ise 118,64 yaralanma/1000 müsabaka olarak bulunmuştur. Müsabaka başına taekwondoda 0,02 yaralanma, para-taekwondoda ise 0,11 yaralanma kaydedilmiştir. Alt ekstremite yaralanmaları para-taekwandoda (33,89 yaralanma/1000 müsabaka) taekwondoya göre (10,51 yaralanma/1000 müsabaka) daha sık görülmüştür.

Sonuç: P-TWD'da yaralanma oranı, TWD’ya göre daha fazla görülmüştür. Bu çalışma, gelecekteki yaralanma izlem çalışmaları ve taekwondo yarışmalarındaki yaralanma sayılarını azaltmak için önleme stratejileri ve önerileri geliştirilmesine yardımcı olacak epidemiyolojik bilgiler sunmaktadır.

Anahtar Sözcükler: Taekwondo, Para-Taekwondo, Yaralanma, İnsidans

Available at: http://journalofsportsmedicine.org and http://dx.doi.org/10.5152/tjsm.2019.139

Cite this article as: Celebi MM, Dundar I, Zergeroglu AM. Injury epidemiyology in elite taekwondo athletes: Retrospective cross sectional study including three international championships. Turk J Sports Med. 2019;54(4):250-4.

\section{GİRIŞ}

Taekwondo (TWD); 600'lü yıllarda ortaya çıkan, el ve ayakla yapılan, Kore kökenli bir uzak doğu savunma sanatı ve dövüş sporudur. 2000 Sidney Olimpiyatlarından bu yana yaz olimpiyatlarında yer almaktadır. Dünya genelinde popüler bir spor olup yaklaşık 120 milyon civarında katılımcısı bulunmaktadır (1). Antrenmanları yaklaşık 2-2,5 saat sürmekte ve bunun 1-1,5 saatlik kısmı aerobik ve esnetme egzersizlerini içermektedir.

Müsabakalarda bel altı vuruşlar yasaktır, 3 devre, 2 dakikalık periyotlar şeklindedir ve aralarda 1 dakikalık dinlenmeler mevcuttur. Yaralanmaların önlenmesi için kask, dişlik, kolluk, yelek (safeguard), bacak, kasık korumaları ile çorap şeklindeki kaval korumalıklarının giyilmesi zorunludur. Çorap, yelek ve kask sensörlüdür. Puanlar vuruşun sertliğine göre sensör algılaması ile değerlendirilmektedir. Sporcu rakibinden puan almak için maksimum kuvvetini uygularken spor ahlakına ve kurallarına saygı göstermelidir.

Ayrıca üst ekstremite engelli sporcular için para-taekwondo (P-TWD) branşı mevcuttur. PTWD müsabakalarında hem bel altı hem de kafaya vuruşlar yasaktır. Dünya Taekwondo Federasyonu (WTF) 2005'te P-TWD Komitesini kurmuştur. WTF'ye göre P-TWD sınıflaması şu şekildedir:

K41= Bilateral omuzdan itibaren tüm kol kaybı
K42= Unilateral omuzdan itibaren kol kaybı ya da bilateral dirsek üzeri kayıp

\section{K43= Bilateral dirsekten itibaren kayıp}

K44= Nörolojik bozukluk (CNS, PNS) monopleji ya da bilateral-unilateral bilekten itibaren kayıp.

Bir sporun yaralanma şeklini ve onun içerdiği risk faktörlerini anlamak güncel spor hekimliği için önemli bir alandır. Diğer birçok sporda olduğu gibi, teaewondodaki elit sportif performansla ilişkili yaralanma potansiyelini bilmek önemlidir. Bu çalışmadaki amacımız da uluslararası turnuvalarda TWD ve P-TWD'nin yaralanma oranlarını belirlemek ve bunlarla ilgili veriler sunmaktır.

\section{GEREÇ VE YÖNTEM}

Antalya'da Kasım 2014'te yapılan 2. Avrupa Kulüpler Taekwondo Şampiyonası, 1. Uluslararası Türkiye Açı Taekwondo Şampiyonası ve 3. Avrupa Para Taekwondo Şampiyonası sırasında yaralanan sporcular 5 hekim tarafından değerlendirilmiş ve yaralanma kayıtları tutulmuştur. Bu çalışmada uluslararası katılımlı üç turnuvada yaralanma verileri kaydedilerek TWD ve P-TWD'de görülen yaralanmaların özellikleri belirlenmeye çalışılmıştır.

Veriler vücut bölgelerine göre sınıflandırılmıștır. $\mathrm{Bu}$ şampiyonalara 1838 TWD ve 74 P-TWD sporcusu katılmıştır. TWD'de 1521, P-TWD'de 
59 müsabaka yapılmıştır. 1000 müsabakadaki yaralanma oranı ve müsabaka başına yaralanma oranı değerlendirilmiștir. Yaralanma verilerini gruplandırmak ve sayılarını belirlemek amacıyla tanımlayıcı istatistik kullanılmıștır.

Kas-iskelet sistemi ve serebral konküzyonlar olarak ikiye ayrılan yaralanmalar baş-boyunda, üst ekstremitelerde, alt ekstremitelerde ve gövdede olmaslarına göre sinıflandırılmaktadır (2). Bölgesel yaralanma tabloları oluştururken Uluslararası Olimpiyat Komitesi (IOC)'nin "Daily Report on Injuries and Illness" formu kullanılmıştır. Çalışmanın etik kurul onayı Ankara Üniversitesi Tıp Fakültesi Etik Kurulundan alınmıştır (Karar No: 1-6-19 ve Karar Tarihi 14.01.2019).

\section{BULGULAR}

Şampiyonalarda 31 TWD ve 7P-TWD sporcusu yaralanmıştır (28 erkek, 10 kadın). P-TWD'de baş-boyun ( 2 vaka), üst ekstremite ( 2 vaka), alt ekstremite (2 vaka) ve 1 gövde yaralanması görülmüştür. TWD'de ise baş-boyun (6 vaka), üst ekstremite ( 9 vaka) ve alt ekstremite (16 vaka) yaralanması görülmüştür. Yaralanma sıklığı TWD'de 20.38 yaralanma/1000 müsabaka, P-TWD'de ise 118,64 yaralanma/1000 olarak kaydedilmiştir. TWD'de müsabaka başına 0,02 yaralanma görülürken, PTWD'de müsabaka başına 0,11 yaralanma görülmüştür. Alt ekstremite yaralanması TWD'de 10,51 yaralanma/1000 müsabaka, PTWD'de 33,89 yaralanma/1000 müsabaka olarak kaydedilmiştir.

Kırık ve büyük eklem çıkığı olguları uygun şartlarda taşınarak hastaneye yönlendirilmiştir. Küçük eklem çıkıkları, laserasyonlar ve kontüzyonlara ayaktan tedavi uygulanmıştır. TWD'de baş-boyun yaralanması olarak birer burun ve gözaltı laserasyonu, göz laserasyonu, göz kapağı kontüzyonu ve 3 travmatik burun kanaması, P-TWD'de ise birer dudak laserasyonu ve konküzyon meydana gelmiștir. TDW'de üst ekstremite yaralanması olarak birer ön kol kontüzyonu, el parmak çıkı̆̆ı, el parmak

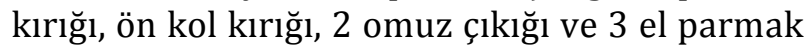
distorsiyonu, P-TDW'de bir omuz çıkığı ve bir ön kol fraktürü meydana gelmiştir. Alt ekstremite yaralanması olarak TWD'de birer diz iç yan bağ yaralanması ve ön çapraz bağ rüptürü, medial menisküs rüptürü, hamstring kontüzyonu, quadriseps femoris straini, 2'şer diz kontüzyonu, ayak parmak kontüzyonu, ayak parmak laserasyonu, 3'er bacak kontüzyonu, ayak bileği distorsiyonu, P-TDW'de ise birer kalça kontüzyonu ve diz kontüzyonu meydana gelmiştir. Gövde yaralanması yalnızca P-TWD’de 1 tane görülmüştür. Kadın ve erkek yaralanma oranları Tablo 1' de verilmiştir.

Tablo 1: Üç uluslararası yarışmada görülen taekwondo yaralanmaları

\begin{tabular}{lccc}
\hline & Erkek & Kadın & Toplam \\
\hline İki uluslararası taekwondo yarışması & & & \\
\hline Sporcu Sayısı & 1100 & 738 & 1838 \\
Müsabaka Sayısı & 939 & 582 & 1521 \\
\hline Yaralanma sayısı & 23 & 8 & 31 \\
Yaralanma/1000 Müsabaka & 24,49 & 13,75 & 20,38 \\
\hline Avrupa Para-Taekwondo Şampiyonası & & & \\
\hline Sporcu Sayısı & 48 & 26 & 74 \\
Müsabaka Sayısı & 48 & 11 & 59 \\
Yaralanma sayısı & 5 & 2 & 7 \\
Yaralanma/1000 Müsabaka & 104,17 & 181,82 & 118,64 \\
\hline
\end{tabular}




\section{TARTIŞMA VE SONUÇ}

Bu çalışmada daha önce yapılmış çalışmalara göre (3-6) daha az yaralanma görülmesi, TWD'de P-TWD'den daha fazla yaralanma görülmesi ve TWD'de alt ekstremite yaralanmasının daha fazla saptanmış olması dikkat çekicidir. Literatür verileriyle klyaslandığında; TWD (69,5 yaralanma/1000 müsabaka) (3), Karate (157,03-179,94 yaralanma/1000 müsabaka) $(4,5)$ ve Wushu (228,07 yaralanma/1000 müsabaka) (6) bu çalışmada yaralanma sayısı daha az bulunmuştur. $\mathrm{Bu}$ çalışmada P-TWD yaralanmalarının da incelenmiş olması özgün bir durumdur. Bazı prospektif çalışmalarda $(3,4)$ yaralanma oranları bu çalışmadan yüksek çıkmıştır. Bunun nedeni çalışma dizaynı olabilir. Bir sistematik derlemede (7) yaralanma oranlarının erkeklerde 20,6/1000 ile $139,5 / 1000$, kadinlarda ise $25,3 / 1000$ ile 105.5/1000 arasında olduğu belirtilmiştir. Bu çalışmada elde edilen veriler bu çalıșma ile uyumludur. P-TWD'de yaralanma oranı TWD'ye göre daha yüksek bulunmuştur.

Birçok dövüş sporunda olduğu gibi, TWD'de de elit düzeyde yaralanma olasıllı̆̆ yüksektir (7). Erkeklerdeki yaralanmaların yaklaşık olarak dörtte biri (29.6\%) baş ve boyun bölgesinde, yarısı $(44.5 \%)$ alt ekstremitede bulunmuştur. Kadınlarda, yaralanmaların $15.2 \%$ 'i baş ve boyun bölgesinde, \%53,1'i alt ekstremitededir. İran'da yapılan bir çalışmada TWD müsabakalarında 204 erkek sporcunun katıldığ 1338 müsabakada 93 yaralanma saptanmıștır, müsabaka başına 0,023 yaralanma ve 69,5 yaralanma/1000 müsabaka olarak kaydedilmiştir (3).

1997 Kanada Ulusal TWD Şampiyonasında 219 erkek, 99 kadın sporcu yaralanma açısından izlenmiştir (8). Erkeklerde 438, kadınlarda 198 müsabaka yapılmış ve erkeklerde 35 , kadınlarda 5 yaralanma saptanmıştır. Erkeklerde 79,9 yaralanma/1000 müsabaka, kadınlarda 25,3 yaralanma/1000 müsabaka olmak üzere toplamda 62,9 yaralanma/1000 müsabaka olarak kaydedilmiştir. Her iki cinsiyette de en fazla alt ekstremite yaralanmaları görülmüştür.
Erkek sporcularda sirasiyla sprain, eklem disfonksiyonu, kontüzyon ile laserasyon, kadın sporcularda da ise en fazla kontüzyon saptanmıştır (8).

Arriaza ve Leyes, 1996 Güney Afrika, 1998 Brezilya, 2000 Almanya Dünya Karate Şampiyonalarında görülen yaralanmaları değerlendirdikleri çalışmalarında bireysel olarak 1763, takım olarak 1074, toplam 2837 müsabakada 891 (maç başına 0,314) yaralanma kaydetmişlerdir (4). Yaralanmaların 448'i $(\% 50,3)$ kontüzyon, 144'ü burun kanaması $(\% 16,2)$ ve 122 'si $(\% 13,7)$ laserasyondur. Yaralanmaların 646'sı yüz bölgesinde iken, 103'ü kafa yaralanması olarak raporlanmıștır. Yaralanmaların 25'inin (\%3) WKF Yaralanma Sinıflandırmasına göre ciddi yaralanma olduğu belirlenmiştir. Yaralanma mekanizmalarına bakıldığında $737 \quad(\% 82,7) \quad$ yaralanmanın yumrukla gerçekleștiği saptanmıştır (4).

Arriaza ve arkadaşları 2002 yılında yapılan kural değişikliklerinin yaralanma siklığına etkisini araştırdıkları bir başka çalışmalarında 2002 İspanya, 2004 Meksika ve 2006 Finlandiya Dünya Karate Şampiyonalarında toplam 2762 müsabakada 497 (maç başına 0,18) yaralanma kaydetmişlerdir (5). Bunlardan 241'i (\%47) kontüzyon, 98'i (\%20) burun kanaması ve 52'si (\%10) laserasyon olarak raporlanırken, yüz yaralanmaları toplam yaralanmaların \%66'sını oluşturmuştur. Yaralanma mekanizması incelendiğinde \%67 ile yumrukla yaralanmanın en sık neden olduğu belirlenmiştir (5).

Yiemsiri ve Wanawan ise 2014 yllında yayınladıkları çalışmada 1. Asya 2009 Dövüş Sporları Oyunları'ndaki Wushu yaralanmalarını takip etmişlerdir (6). 38 erkek, 22 kadın sporcunun katıldığı 114 müsabakada $26(228,07$ yaralanma/1000 müsabaka) yaralanma saptanmıştır. Wushu sporunda taekwondodan farklı olarak koruyucu ekipman azdır ve yüze yumruk serbest olup, müsabakaya devam edemeyen 6 sporcudan 2 tanesinin konküzyon yaralanması geçirdiği rapor edilmiştir (6).

Birçok çalışmada TWD yaralanmalarının daha çok alt ekstremitede olduğu belirtilmiştir (1, 710). Altarriba ve arkadaşlarının bir çalışmasında 
diz yaralanmaları başta olmak üzere alt ekstremitede \%70,7 oranında yaralanma saptanmıştır (1). Kazemi ve arkadaşları ise en fazla alt ekstremite, sonra üst ekstremite yaralanması bildirmişlerdir (9). Bazı çalışmalarda ise üst ekstremite yaralanmaları daha çok görülmüş olup $(3,11)$, bunlardan birinde saptanan 9 kırık vakasının 8 tanesinin üst ekstremitede görüldüğü bildirilmiştir (3). 1983'te Danimarka'da yapılan 6. Dünya Taekwondo Şampiyonasında görülen yaralanmalar da daha çok baş-boyun bölgesinde saptanmıştır (12). Bu çalışmada ise TWD'de en sık alt ekstremite yaralanmaları görülmüştür.

Yaralanmalardaki bölgesel farklılıklar müsabakaların yapıldığı tarihte koruyucu ekipman kullanımı, müsabaka kuralları ve ülkenin TWD açısından kullandığı taktiğe bağlı olarak değişmektedir. TWD'de karate, Wushu gibi spor dallarına göre daha az yaralanma olmaktadır. Sık görülen yaralanmaların türü (kontüzyon gibi) göz önüne alındığında TWD sporundaki koruyucu ekipmanların yaralanmaları önlemede önemli olduğu görülmektedir. Müsabaka kurallarının ve bu kuralların hakemler tarafindan uygulanma şeklinin de yaralanmalardan korunmada önemli olduğu düşünülmektedir. Bunun yanında yaralanma sıklığı müsabakalarda mutlaka sağlık ekibinin bulunması gerektiğini ortaya koymaktadır.

$\mathrm{Bu}$ çalışmanın dikkate alınması gereken bazı kısıtlılıkları vardır. Birincisi ve belki de en önemlisi, retrospektif bir tasarıma sahip olmasıdır. Demografik verilerin tam olarak verilememesi, yaralanma anının veya yaralanma oranlarının keskin bir doğrulukla hesaplanamamış olma olasılığı veya önceki yaralanma bilgilerinin eksikliği önemli kısıtlılıklarıdır. Bir diğer önemli kısıtlılık da müsabaka öncesi yaralanma durumunun bilinmemesi ve yaralanma sonrası spordan uzak kalma sürelerinin sorgulanamamış olmasıdır.
İleriki çalışmalarda sadece müsabaka değil, antrenman dönemi yaralanmalarının da izlenmesi önem arz etmektedir. Böylece alınması gereken önlemler de daha iyi belirlenebilir.

\section{KAYNAKLAR}

1. Altarriba-Bartes A, Drobnic F, Til L, et al. Epidemiology of Injuries in Elite Taekwondo Athletes: Two Olympic Periods Cross-Sectional Retrospective Study. Br J Sports Med Open. 2014; 4: e004605

2. Haddad $M$, editör. Performance Optimization in Taekwondo: From Laboratory to Field. Injuries in Taekwondo. USA; OMICS Group eBooks. 2014; p. 114.

3. Ziaee V, Rahmani S-H, Rostami M. Injury Rates in Iranian Taekwondo Athletes; A Prospective Study. Asian J Sports Med. 2010; 1: 23.

4. Arriaza R, Leyes M. Injury Profile in Competitive Karate: Prospective Analysis of Three Consecutive World Karate Championships. Knee Surg Sports Traumatol Arthrosc. 2005; 13: 603-7.

5. Arriaza R, Leyes $\mathrm{M}$, Zaeimkohan $\mathrm{H}$, et al. The Injury Profile of Karate World Championships: New Rules, Less Injuries. Knee Surg Sports Traumatol Arthrosc. 2009; 17: 1437-42.

6. Pichet Yiemsiri, Amarin Wanawan. Prevalence Of Injuries In Wushu Competition During The 1st Asian Martial Arts Games 2009. J Med Assoc Thai. 2014; 2: 9-13

7. Pieter W, Fife GP, O'Sullivan DM. Competition Injuries In Taekwondo: A Literature Review and Suggestions For Prevention an Surveillance. Br J Sports Med. 2012; 46: 485-1.

8. Kazemi M, Pieter W. Injuries at a Canadian National Taekwondo Championships: a prospective study. BMC Musculoskeletal Disord. 2004; 5:22.

9. Kazemi M, Shearer H, Choung YS. Pre-competition Habits and Injuries in Taekwondo Athletes. BMC Musculoskeletal Disord. 2005; 6: 26.

10. Ramazanoglu N. Effectiveness of Foot Protectors and Forearm Guards in Taekwondo. Archives of Budo. 2012; 8: 207-1.

11. Lystad RP, Graham PL, Poulos RG. Exposure-adjusted Incidence Rates and Severity of Competition Injuries in Australian Amateur Taekwondo Athletes: A 2-year Prospective Study. Br J Sports Med. 2013; 47: 441-6.

12. Siana JE, Borum $P$, Kryger H. Injuries in Taekwondo. Br J Sports Med. 1986; 20: 165-6. 